\title{
Effects of nicotine on spontaneous locomotor activity in rats having high and low basal activity levels*
}

\author{
CHARLES J. MELISKA, KEVIN W. FITZPATRICK, and JERRY E. ROSINE \\ Monmouth College, Monmouth, Illinois 61462
}

\begin{abstract}
Two groups of six rats each, preselected for high and low rates of spontaneous wheelrunning activity, were tested immediately following injections of either distilled water or nicotine hydrogen tartrate. At $0.10,0.20,0.40$, and $0.80 \mathrm{mg} / \mathrm{kg}$, nicotine depressed wheelrunning significantly in the high-activity Ss during the first $20 \mathrm{~min}$ after the injection. The performance of the low-activity Ss was not significantly affected by any dose of the drug. No evidence of tolerance development to the depressant actions of the drug was obtained.
\end{abstract}

Nicotine has been reported either to stimulate or to depress spontaneous activity in rodents, depending upon several factors, including the dosage employed (Silvette, Hoff, Larson, \& Haag, 1962; Pradhan, 1970), the strain of animal tested (Morrison \& Lee, 1968), and the basal activity levels of test Ss (Meliska \& Rosine, unpublished observations, 1972). Morrison and Stephenson (1972) have also noted that either stimulation or depression may occur, depending upon the animals' past experience with the drug; inexperienced Ss may show behavioral depression, while experienced Ss may evidence stimulation.

The present study was designed to test, within a single design, whether rats selected for either high or low spontaneous locomotor activity would be differentially affected by nicotine at a range of dose levels. On the basis of the findings cited above, it was expected that nicotine would depress the spontaneous wheelrunning of highly active Ss, while increasing the activity of low-activity Ss.

\section{METHOD}

\section{Subjects}

Twelve experimentally naive male Harlan/Wistar rats, about 120 days old at the start of the experiment, served as Ss. They were housed individually in wire-mesh cages, with food and water ad lib throughout the experiment. Mean body weights increased from 475 to $502 \mathrm{~g}$ over the 11-day period of data collection.

\footnotetext{
Apparatus

Six standard activity wheels (Wahmann Mfg., Baltimore, Md.) were used. Wheels were 12 in. in diam and $4 \frac{1}{2}$ in. wide. Each wheel was equipped with a mechanical counter that recorded wheel revolutions in either direction of rotation. A metal sliding door at the entrance to each wheel was closed to prevent escape of the $\mathrm{S}$ during testing.

\section{Procedure}

The experiment consisted of two phases: (1) pretest screening, and (2) drug trials.
}

*This study was supported in part by a grant from the Faculty Development Committee of Monmouth College.
During the pretest period, a total of 25 rats were screened for spontaneous locomotor activity. For 6 consecutive days, each S was removed from his home cage, weighed, and placed into a wheel for $30 \mathrm{~min}$. On the basis of their scores, the six most active $(\overline{\mathrm{X}}=63.2 \mathrm{revs} / 30 \mathrm{~min})$ and six least active $(\bar{X}=0.6 \mathrm{revs} / 30 \mathrm{~min})$ animals were assigned to the "high activity" (HA) and "low activity" (LA) groups, respectively. For the next 5 days, animals were given IP injections of distilled water $(1.0 \mathrm{cc} / \mathrm{kg} \mathrm{b.w.)}$ and immediately placed into the wheels for 1 full hour. Revolutions were recorded for three consecutive 20 -min intervals, hereafter referred to as $T_{1}, T_{2}$, and $T_{3}$, respectively. Each rat was tested in the same wheel throughout the experiment. Testing took place in the morning.

Drug trials were begun immediately after these pretest trials, and this phase of the experiment was completed over 11 consecutive days. Each $S$ received an IP injection of either distilled water (DW) or nicotine hydrogen tartrate at one of the following doses: $0.05,0.10,0.20,0.40$, or $0.80 \mathrm{mg} / \mathrm{kg} \mathrm{b.w}$. Fresh drug solutions were prepared in distilled water on each drug test day. Each $S$ received each of the six treatments according to a Latin square design. As a control for carryover effects, drug days were alternated with control days on which all Ss received DW. This meant that all drug injections were separated by $48 \mathrm{~h}$, with one exception: As part of the Latin square, each S received a DW "dose" on the drug day which followed the $0.80 \mathrm{mg} / \mathrm{kg}$ injection. This provided an extra DW administration between the $0.80 \mathrm{mg} / \mathrm{kg}$ and $0.05 \mathrm{mg} / \mathrm{kg}$ treatments, so that these doses were separated by 96 , rather than $48 \mathrm{~h}$.

\section{RESULTS}

Preliminary analysis indicated that variances of the HA and LA groups were inhomogeneous $(F=91.8$, $\mathrm{df}=107 / 107, \mathrm{p}<.001)$. Therefore, wheelrunning scores of the HA and LA groups were analyzed separately.

\section{HA Group}

Using a repeated-measures, Latin square ANOVA, wheel revs/20 min were analyzed as a function of order (day) of drug administration (1st through 6th), $\mathrm{drug} /$ dose (DW, 0.05, 0.10, 0.20, 0.40, and $0.80 \mathrm{mg} / \mathrm{kg}$ nicotine $)$ and time interval $\left(\mathrm{T}_{1}=0.20 \mathrm{~min}\right.$; $\mathrm{T}_{2}=20-40 \mathrm{~min} ; \mathrm{T}_{3}=40-60 \mathrm{~min}$ ). As Table 1 indicates, time and drug/dose factors were significant, as was the Time by Drug/Dose interaction. Analyses of simple effects showed that the drug/dose factor was significant 
Table 1

Summary of ANOVA on Wheel Revolutions/20 Min as a Function of Order, Drug/Dose, and Time Since Injection

\begin{tabular}{lrrrc}
\hline Source & \multicolumn{1}{c}{ SS } & df & \multicolumn{1}{c}{ MS } & \multicolumn{1}{c}{ F } \\
\hline Order & 385.75 & 5 & 77.15 & 0.80 \\
Drug/Dose & 1379.53 & 5 & 275.91 & $2.86^{*}$ \\
Subjects & 6990.42 & 5 & 1398.05 & - \\
Time & 5943.50 & 2 & 2971.75 & $30.80 \dagger$ \\
Time by Order & 1800.17 & 10 & 180.02 & 1.87 \\
Time by Drug/Dose & 2167.72 & 10 & 216.77 & $2.25^{*}$ \\
Time by Subjects & 2318.83 & 10 & 231.88 & $2.40^{*}$ \\
Error (Pooled) & 5789.00 & 60 & 96.48 & - \\
Total & 26774.92 & 107 & & \\
\hline \multicolumn{4}{c}{${ }^{*} p<.05$} & \multicolumn{5}{c}{$t p<.001$}
\end{tabular}

during $T_{1}(p<.001)$, but not during $T_{2}$ and $T_{3}$. That is, nicotine significantly depressed wheelrunning during the first 20 min postinjection, but not during the last two 20-min intervals. Duncan's multiple range tests showed that during $T_{1}$, wheelrunning was reduced significantly below control by all doses of the drug except $0.05 \mathrm{mg} / \mathrm{kg}$. These results are represented in Fig. 1 .

Further analyses revealed that, across drug treatments, wheelrunning was significantly greater during $T_{1}$ than during $T_{2}$ and $T_{3}$, with the exception of the 0.10 and $0.80 \mathrm{mg} / \mathrm{kg}$ doses. At these doses, the decline in wheelrunning from $T_{1}$ to $T_{2}$ was not significant. This was apparently attributable to the drug-produced depression in responding at these doses, which reduced wheelrunning during $T_{1}$ to a level comparable to $T_{2}$.

Table 1 also indicates that neither the order effect nor the Order by Time interaction was significant $(\mathrm{p}>.05)$. Thus, the degree of reduction in wheelrunning due to nicotine was essentially the same across repeated administrations of the drug, indicating a lack of tolerance development. These data are represented in

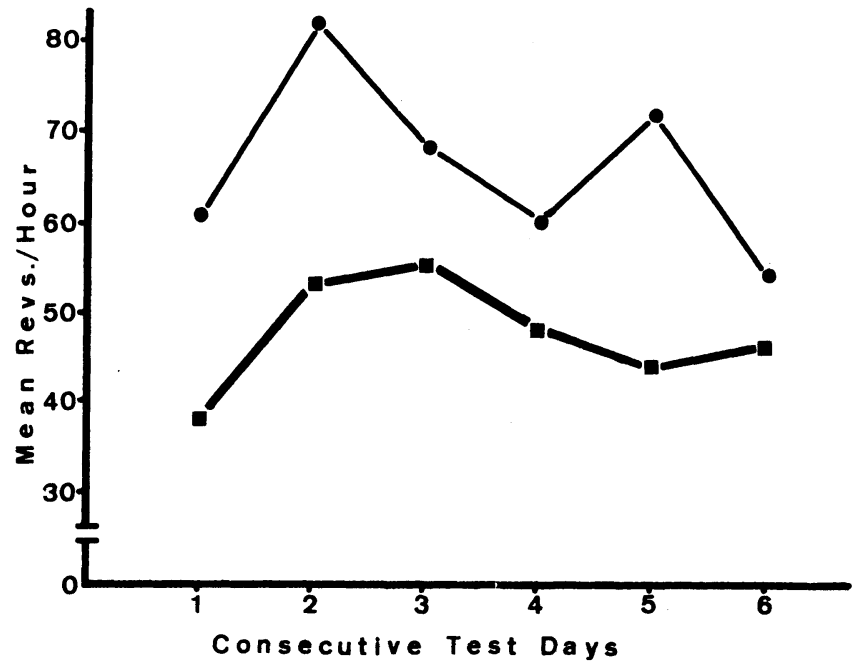

Fig. 2. Effects of consecutive druggings on wheelrunning across test days. (nicotine test days, - $\square$, preceding control days, $\bullet-\bullet$ ).

Fig. 2, which also shows the means of each preceding control day for comparison.

\section{LA Group}

Wheelrunning scores of the LA group (Fig. 1, closed bars) were subjected to the same analyses described for HA animals. No significant main effects nor interactions among any factors were found. There was also no significant effect of order of drug administration.

\section{Summary of Results}

The important results may be summarized as follows: (1) Nicotine hydrogen tartrate, at $0.10,0.20,0.40$, and $0.80 \mathrm{mg} / \mathrm{kg}$, significantly depressed the spontaneous

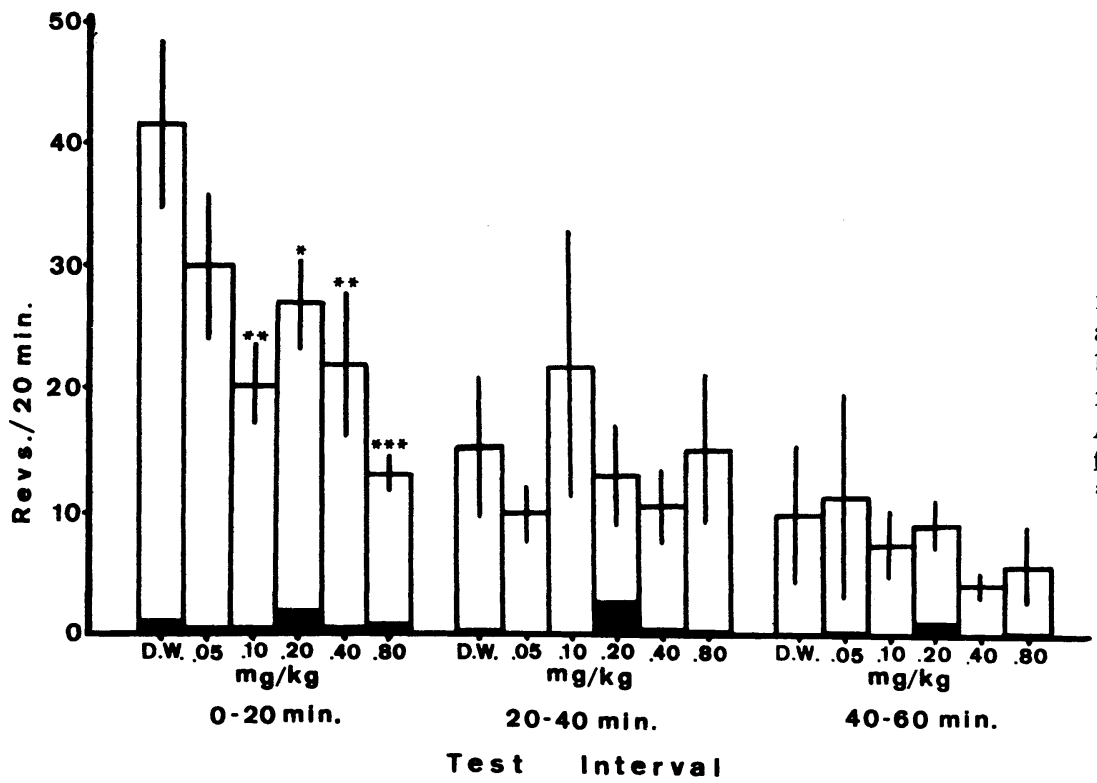

Fig. 1. Effects of various doses of nicotine hydrogen tartrate on wheelrunning activity in HA (open bars) and LA (closed bars) rats at three time intervals following injection. Vertical lines represent S. E. units. Asterisks indicate significance of differences from saline control: ${ }^{*} \mathrm{p}<.05,{ }^{* *} \mathrm{p}<.01$, $* * * \mathrm{p}<.001$. 
wheelrunning of HA Ss during the first $20 \mathrm{~min}$ of testing, but not thereafter. (2) Spontaneous wheelrunning activity of LA Ss was not significantly affected by any dose of nicotine. (3) No significant tolerance development to the drug was detected after 5 days of nicotine administration.

\section{DISCUSSION}

The present results confirm the prediction that nicotine would retard the spontaneous locomotor activity of HA rats. The degree of depression produced appears to be fairly dose-dependent over the range tested, in contrast to reports (Silvette et al, 1962; Pradhan, 1970) of stimulation at low dosages. The depression effect occurred early in testing, during the first $20 \mathrm{~min}$ after the nicotine injection. Nicotine-produced reductions in wheelrunning during the last two 20-min intervals did not reach statistical significance.

The failure to detect any signs of tolerance development after repeated drug administrations contrasts with the recent findings of Morrison and Stephenson (1972) who reported that nicotine depressed activity during the first 3 days of testing, but stimulated activity thereafter. Methodological differences between the present study and Morrison and Stephenson (1972) may account for this discrepancy. For example, Morrison and Stephenson (1972) examined an activity task which involved free exploration in a darkened container, while the present work tested running in a well-illuminated wheel. It is quite possible that the different behaviors involved in these two tests are differentially sensitive to nicotine. Nicotine may potentiate exploration, while depressing wheelrunning; or, the stimulation effect may be contingent upon, or potentiated by, reduced illumination.

A second methodological difference between the present study and Morrison and Stephenson (1972) involves trial spacing. Ss were given 10 consecutive daily drug injections in the latter study while, in the present work, nicotine was given only on 6 alternate days with control injections in between. Furthermore, as a consequence of the Latin-square sequence of drug administration, the highest dose $(0.80 \mathrm{mg} / \mathrm{kg})$ was always followed by the DW dose, thereby providing three nondrug days between the 0.80 and $0.05 \mathrm{mg} / \mathrm{kg}$ doses. This extra spacing of drug treatments may be adequate to prevent the development of the tolerance observed by Morrison and Stephenson (1972).
The prediction that nicotine would stimulate activity in LA Ss was not supported. No indication of consistent behavioral stimulation was observed at any dose level of the drug. This finding is contrary to those of Meliska and Rosine (unpublished research, 1972) who observed stimulation of activity in LA rats with a $0.10-\mathrm{mg} / \mathrm{kg}$ dose of nicotine. Morrison and Lee (1968) also observed increased exploratory activity with nicotine in a low-mobility strain of (Wistar) rats-the same strain used in the present study. While no obvious explanation for this discrepancy suggests itself, it is possible that, by selecting rats for the extremes of activity and inactivity, some abnormally inactive Ss were chosen-Ss which were particularly insensitive to the stimulant actions of nicotine. However, this explanation is not particularly satisfying in view of Morrison and Lee's (1968) observation that, of the four strains they tested, Wistar rats proved to be the most susceptible to stimulation by nicotine.

While a substantial amount of current literature suggests that nicotine can stimulate activity under some circumstances, it also appears that nicotine has produced activity reductions in a number of situations (Dews, 1953; Bovet, Bovet-Nitti, \& Oliverio, 1967; Morrison \& Armitage, 1967; Morrison, 1969). Apparently, the critical variahles which determine whether behavioral stimulation or depression will occur following nicotine injection remain to be identified.

\section{REFERENCES}

Bovet, D., Bovet-Nitti, F., \& Oliverio, A. Action of nicotine on spontaneous and acquired behaviour in rats and mice. Annals of the New York Academy of Sciences, 1967, 142, 261-267.

Dews, P. B. The measurement of the influence of drugs on voluntary activity in mice. British Journal of Pharmacology, $1953,8,46-48$.

Morrison, C. F. Effects of nicotine on motor coordination and spontaneous activity in mice. Journal of Pharmacy \& Pharmacology, 1969, 21, 35-37.

Morrison, C. F., \& Armitage, A. K. Effects of nicotine upon the free-operant behavior of rats and the spontaneous locomotor activity of mice. Annals of the New York Academy of Sciences, 1967, 142, 268-276.

Morrison, C. F., \& Lee, P. N. A comparison of the effects of nicotine and physostigmine on a measure of activity in the rat. Psychopharmacologia, 1968, 13, 210-221.

Morrison, C. F., \& Stephenson, J. A. The occurrence of tolerance to a central depressant effect of nicotine. British Journal of Pharmacology. 1972, 45, 151-156.

Pradhan, S. N. Effects of nicotine on several schedules of behavior in the rat. Archives Internationales de Pharmacodynamie et de Therapie, 1970, 183, 127-138.

Silvette, H., Hoff, E. C., Larson, P. S., \& Haag, H. B. The actions of nicotine on central nervous system functions. Pharmacological R eview, 1962, 14, 137-173.

(R eceived for publication July 25, 1973; revision received July $23,1974$. ) 